\title{
Tuberculosis resistente y extrapulmonar: dos retos para el médico de hoy
}

\author{
Resistant and extrapulmonary tuberculosis: two \\ challenges for today's clinician
}

Juan Carlos Rojas Puentes, MD.

En este número de la revista se publican dos casos de tuberculosis que reflejan de manera perfecta la problemática actual en el abordaje diagnóstico y terapéutico de la enfermedad.

En uno de éstos, los autores presentan el caso de un paciente con derrame pericárdico, en quien los estudios de líquido pericárdico y la biopsia pericárdica mostraron hallazgos compatibles con pericarditis tuberculosa, entidad que, como se comenta en el artículo, es poco frecuente pero conlleva gran mortalidad si no se realiza un diagnóstico oportuno. Puede derivar de reactivaciones tardías o deberse a extensiones, al pericardio, de focos pulmonares, pleurales y ganglionares subcarinales vecinos al corazón $(1,2)$.

A propósito de este caso es recomendable hacer énfasis en el diagnóstico precoz, para lo cual es esencial tener en cuenta esta etiología ante cualquier compromiso pericárdico sin causa aparente. Conviene, así mismo, llamar la atención respecto a la necesidad de efectuar estudios complementarios al momento de realizar el diagnóstico, incluyendo el procesamiento de muestras para cultivos, sin olvidar que tienen un bajo rendimiento ya que solo son positivas en menos de un tercio de los casos $(1,2)$.
Otras ayudas diagnósticas útiles a la hora de abordar el paciente con pericarditis tuberculosa, como las pruebas de genotipificación, la medición de interferón gamma y la adenosín deaminasa (ADA) sirven de apoyo para la toma de decisiones rápidas y son útiles en pacientes inmunocomprometidos, en quienes las pruebas microbiológicas habituales tienen aun menos utilidad (3). Si la pericarditis tuberculosa se deja evolucionar de forma espontánea, puede seguir un curso crónico, produciendo un mezcla variable de fibrosis, caseosis y compromiso cardíaco de vecindad, finalizando en la conocida pericarditis constrictiva, entidad de pronóstico reservado, en la cual la pericardiectomía no siempre es efectiva y conlleva gran riesgo $(1,2)$.

Es una de las formas en las que, como se afirma en el reporte, está especialmente indicado el manejo con esteroides sistémicos además del tratamiento con fármacos antituberculosos, demostrándose en varios estudios observacionales mayor reabsorción del líquido y menor evolución hacia pericarditis constrictiva $(1,2)$.

De otro lado, al abordar el tema de resistencia, se presenta el caso de una paciente sin factores de riesgo, con historia de contacto con paciente con tuberculosis sensible, lo que invita
Internista-Neumólogo. Pereira, Colombia. Correspondencia: Dr. Juan Carlos Rojas Puentes. Correo electrónico: jrojaspuentes@gmail.com

Recibido: 7-07-2013. Aceptado: 17-08-2013. 
precisamente a preguntarse si los casos de tuberculosis con resistencia primaria son más frecuentes en nuestro medio y si existen otros factores de riesgo que usualmente no identificamos. Para este caso llama la atención el antecedente de uso de antibióticos, por lo que en un comienzo se consideró una neumonía adquirida en la comunidad. De igual forma, el caso demuestra cómo el compromiso endobronquial puede llevar a consecuencias catastróficas de la enfermedad, como la necesidad de intervenciones quirúrgicas extensas con alto grado de dificultad y riesgo, así como a pérdidas funcionales importantes.

A pesar del mejor entendimiento desde el punto de vista molecular e inmunológico de la dinámica del bacilo tuberculoso y sus mecanismos de resistencia, continúan reportándose tasas sumamente altas de multidrogorresistencia alrededor del mundo. Colombia, con una prevalencia intermedia para tuberculosis y un porcentaje alto de subdiagnóstico, no es la excepción; según datos del Instituto Nacional de Salud (INS), se estima una prevalencia de 2,3\% y $33 \%$ para multidrogorresistencia (MDR) en pacientes nuevos y previamente tratados, respectivamente (4).

Desde el punto de vista histórico, conforme han aparecido los medicamentos antituberculosos se han descrito fenómenos de resistencia. El primer medicamento utilizado contra la enfermedad fue la estreptomicina, hacia el año de 1944, cuando por primera vez se describió un tratamiento exitoso con este fármaco en monoterapia; sin embargo, fue hasta 1948 que se diseñó el primer estudio clínico controlado en pacientes con tuberculosis, en el que se utilizó estreptomicina como único medicamento, reportándose como resultado una proporción importante de recaídas y fracasos, que condujo a sospechar por primera vez el fenómeno de resistencia (5).

Hacia 1951, se introdujo un derivado del ácido nicotínico conocido como isoniazida, que mostró mejoría clínica importante en pacientes tuberculosos, llevando rápidamente a su introducción al tratamiento y uso generalizado, constituyéndose en uno de los principios básicos del manejo (utilización de al menos tres medicamentos) con el empleo conjunto de isoniazida, estreptomicina y ácido para-amino salicílico (PAS). Posteriormente, con la aparición de la rifampicina hacia 1966 y su uso generalizado hacia finales de los setenta, se describió, en conjunto con la epidemia del síndrome de inmunodeficiencia adquirida (SIDA) hacia inicio de los ochenta, la resistencia a isoniazida y rifampicina, considerados los medicamentos más potentes hasta ahora disponibles, convirtiéndose así la tuberculosis multidrogorresistente (TBMDR) en un problema serio de salud pública mundial (5).

A diferencia de otro tipo de bacterias en las que generalmente los mecanismos son trasmitidos a partir de elementos móviles en el genoma (plásmidos y transposones), en Mycobacterium tuberculosis la resistencia se debe a mutaciones cromosómicas que se presentan en una frecuencia de 10-6-10-8 divisiones que se dan de acuerdo con el tipo de exposición a medicamentos; así que para cuatro medicamentos la probabilidad de desarrollar resistencia sería del orden de 10-27, situación prácticamente imposible en los esquemas actuales de tratamiento (6).

Existen tres tipos principales de resistencia del $M$. tuberculosis frente a los medicamentos. La resistencia natural es aquella que se presenta sin que la cepa de micobacteria haya estado expuesta al medicamento y se explica por la existencia de mutaciones que ocurren al azar como parte de un ciclo evolutivo; tiene mayor posibilidad de aparecer en poblaciones muy numerosas de micobacterias, siendo ejemplo clásico las que se localizan en las cavernas dado el alto número de éstas existentes allí. La resistencia primaria ocurre en enfermos que nunca han recibido tratamiento antituberculoso, y se da típicamente en pacientes que son contacto de enfermos con algún tipo de resistencia; el límite de tiempo de tratamiento previamente recibido considerado para diferenciar una resistencia primaria de una adquirida es de un mes. Por último, está la resistencia secundaria, adquirida, o resistencia en enfermos previamente tratados, la cual resulta de la administración incorrecta de medicamentos antituberculosos, bien sea a dosis inadecuadas, a dosis parciales o en monoterapia; guarda una estrecha relación con fenómenos de abandono, tratamiento irregular y recaídas tempranas a los tratamientos (6).

Conscientes de la necesidad de poder acceder a un diagnóstico temprano y aprovechando el conocimiento del genoma del $M$. tuberculosis, la comunidad científica desarrolló en los últimos años las conocidas pruebas de genotipificación, que tienen como gran 
ventaja, no solo la rápida identificación de la micobacteria, sino la de genes asociados con resistencia, superando los métodos de fenotipificación convencionales, los cuales requieren un tiempo mayor para suministrar un resultado (7).

Con estas nuevas ayudas ya es posible pensar en tener el diagnóstico de tuberculosis resistente en cuestión de horas, lo que, por supuesto, redundará en tratamientos tempranos y dirigidos. En la actualidad existe gran variedad de pruebas de genotipificación, siendo las más utilizadas, el sistema de detección de PCR en tiempo real $\left(\right.$ GenXpert $\left.^{\mathbb{R}}\right)$ y el Genotype ${ }^{\circledR} M T B D R$ plus (7). Este tipo de pruebas permite la detección de mutaciones con ayuda de sondas de ADN marcadas; para ello se amplifica la región en donde se sospecha la mutación causante de resistencia y se analiza según la fluorescencia del producto generado, identificándose mutaciones en $R p o B, K a t G$, inh $A$ y embB. Pueden emplearse en líquidos paucibacilares, así como en muestras de esputo y tejido, permitiendo una gran versatilidad (8).

El GenXpert ${ }^{\circledR}$ no solo permite la identificación del $M$. tuberculosis, sino que detecta las mutaciones en el gen $R p o B$, el cual está relacionado con resistencia a la rifampicina. Si se tiene en cuenta que el $95 \%$ de las cepas que son resistentes a rifampicina también lo son a isoniazida, puede decirse que con esta prueba se llega al diagnóstico de TBMDR de una forma muy rápida y precisa, si se compara con los métodos tradicionales $(9,10)$. Existe ahora un gran interés por los organismos internacionales en salud (OMS/OPS) en posicionar esta técnica alrededor del mundo como pilar en el diagnóstico rápido de las formas de multidrogorresistencia. Su gran ventaja está dada en que si bien es una técnica de biología molecular, no requiere el apoyo de un laboratorio sofisticado y tampoco de personal con altos estándares académicos, y se reportan resultados en dos horas $(9,10)$.

La prueba está claramente dirigida a poblaciones con alta prevalencia de resistencia y pacientes con VIH. Su principal desventaja está dada por los resultados falsos positivos reportados en poblaciones con baja prevalencia de la enfermedad. Ha sido validada en múltiples escenarios clínicos, predominantemente en pacientes con baciloscopias positivas, reportándose un rendimiento de la prueba para el diagnóstico de multidrogorresistencia del $95 \%$ tanto en sensibilidad como en especificidad. En los pacientes con baciloscopias negativas después de la recolección y procesamiento de tres muestras, se reporta un rendimiento máximo del $80 \%$ (11).

La prueba Genotype ${ }^{\circledR} M T B D R$ plus, aventaja al GenXpert ${ }^{\mathbb{R}}$, en que no solo detecta de forma directa resistencia a la rifampicina, sino que identifica mutaciones en otros genes como el $K a t G$ y el $i n h A$, los cuales están relacionados con resistencia a isoniazida, incluso este último también asociado con resistencia a etionamida $(12,13)$.

En tabla se resumen las principales mutaciones relacionadas con resistencia y si hay disponibilidad en la actualidad de detección mediante prueba rápida $(8,14)$.

Tabla.

\begin{tabular}{|l|l|l|}
\hline \multicolumn{1}{|c|}{ Agente terapéutico } & \multicolumn{1}{|c|}{ Mecanismo genético } & Detección rápida \\
\hline Rifampicina & Mutación gen RpoB & $\mathrm{Si}$ \\
\hline Isoniazida & Mutaciones en el gen KatG inhA y aphC & $\mathrm{Si}$ \\
\hline Pirazinamida & Mutaciones Pnca & No \\
\hline Etionamida & Sobreproducción de Rv 3855 (EtaR) & No \\
\hline Etambutol & Sobre-expresión emb mutación del codón 306, 330 and 630 & $\mathrm{Si}$ \\
\hline Fluoroquinolonas & Mutación gyrA codón 94, sustituciones A90V,S91P y 88C & $\mathrm{Si}$ \\
\hline Estreptomicina & Mutaciones en Rrs y RpsL & No \\
\hline Amikacina/kanamicina & Rrs mutación de nucleótidos 1400G y 11401G & Si (amikacina) \\
\hline
\end{tabular}


En conclusión, la mayor frecuencia con la que se presentan en la actualidad tanto los casos de tuberculosis extrapulmonar como los de tuberculosis resistente, plantean un gran reto en el ejercicio clínico diario, frente al cual el médico debe responder haciendo uso adecuado de todas las ayudas diagnósticas disponibles en el momento y promoviendo escenarios de investigación que ayuden a entender mejor el comportamiento de la enfermedad y la utilidad de las nuevas tecnologías.

\section{Bibliografía}

1. Farga V, Caminero J. Tuberculosis. Tercera edición 2011. Santiago, Buenos Aires: Editorial Mediterráneo.

2. Mayosi BM, Burgess LJ, Doubell AF. Tuberculous pericarditis. Circulation. 2005;112:3608-16.

3. Pandie S, Peter J, Kerbelker Z. BMC Medicine. Diagnostic accuracy of quantitative PCR (Xpert MTB/RIF) for tuberculous pericarditis compared to adenosine deaminase and unstimulated interferon- $\gamma$ in a high burden setting: a prospective study. BMC Medicine 2014;12:101.

4. Torres C, Awad C, Dennis R. Guía para el manejo programático de pacientes con tuberculosis farmacorresistente en Colombia 2012. Bogotá: Ministerio de la Protección Social, Fundación Neumológica Colombiana, Instituto Nacional de Salud. Organización Panamericana de la Salud.
5. Keshavjee S, Farmer P. Tuberculosis, Drug resistance, and the history of modern medicine. N Engl J Med. 2012;367:931-6.

6. Caminero J. Multidrug-resistant tuberculosis: epidemiology, risk factor and case finding. Int J Tuberc Lung Dis. 2010;14:382-390.

7. Yew W, Zhang Y. Mechanism of drug resistance in Mycobacterium tuberculosis. Int J Tuberc Lung Dis. 2009;13:1320-1330.

8. Cuevas C; Zenteno R. tuberculosis drogorresistente: mecanismos moleculares y métodos diagnósticos. Enferm Infecc Microbiol Clin. 2010;28:6221-628.

9. Van rie A, Page L, Scott L. Xpert MTB/RIF for point of care diagnosis of TB in high HIV burden, resource-limited countries: hype o hope? Expert Rev Mol Diagn. 20101;10:937-946.

10. Lawn S, Nicol M, Xpert MTB/RIF assay: Development, evaluation and implementation of a new rapid molecular diagnostic for tuberculosis and rifampicin resistance. Future Microbiol. 2011;6:1067-1082.

11. Boehme C, Nabeta P, Hillemann D. Rapid molecular detection of tuberculosis and rifampin resistance. N Engl J Med. 2010;363:1005-1015.

12. Arentz M, Sorensen B, Horne DJ, Walson JL. Systematic review of the performance of rapid rifampicin resistance testing for drug-resistant tuberculosis. Plos One. 2013;8:e76533.

13. Vigneshwaran M, Wang S, Inci F, De Libero G. Emerging technologies for monitoring drug-resistant tuberculosis and the point-of-care. Adv Drug Deliv Rev. 2014 (in Press).

14. Georghiou S, Magana M, Garfein R, Catanzaro D, Cantanzaro A. Evaluation of genetic mutations associates with Mycobacterium tuberculosis resistance to amikacina, kanamycin, capreomycin: a systematic review. Plos ONE. 2012;7:e33275. 